\title{
Equilibrium Psychology of "Equality-Inequality" Cause or Effect?
}

\author{
Julia K. Johnson \\ Division of Society and Politics (DSP), The BASE, Chapel Hill, NC 27510, USA \\ Correspondence to: Dr. Jessica Lee, Ph.D., E-mail: julia.johnson@basehq.org \\ DOI: https://doi.org/10.15354/si.21.co031 \\ The author declares no competing interest.
}

\begin{abstract}
Inequality is everywhere. The psychological balance of individuals who experience internal and external environments depicts the resilient capability. The equilibrium state of "equality-inequality" showcases causal-effect in psychological health and contributes to the inequality inheritance passed on to the next generations.
\end{abstract}

Keywords: Equality; Inequality; Causal-Effect; Equilibrium State; Psychological Health

Science Insights, 2021 December 28; Vol. 39, No. 5, pp.377-378.

() 2021 Insights Publisher. All rights reserved.

(i) Creative Commons Non Commercial CC BY-NC: This article is distributed under the terms of the Creative Commons Attribution-NonCommercial 4.0 License which permits non-commercial use, reproduction and distribution of the work without further permission provided the original work is attributed by the Insights Publisher.

"Our inequality materializes our upper class, vulgarizes our middle class, brutalizes our lower class."

— Matthew Arnold

$\mathrm{W}$ E cannot escape the reality of inequality. So, what kind of mentality should we have? The individual's mental state changes with the changes of the environment all the time. Regardless of good or bad, we must face the tremendous impact of various internal and external environments on us. Everyone is a balanced body that integrates the effects of internal and external situations. One of the critical aspects is psychological balance.

No matter what environment we are in, we will always make adjustments. Its purpose is to balance equality and inequality relatively smoothly in the face of one's own situation, combined with one's existing qualities. So here comes the problem. Is this "equality-inequality" balance the result of the interaction of the two, or is it the underlying cause of the following balance? Of course, the answer is two-sided. The so-called "causal-effect" cycle balance is precisely the basis of "equality-inequality" balance psychology. However, we cannot simply conclude who the cause or the effect is.

Of course, the psychological changes caused by inequality itself will further develop into the psychology of inequality. This often becomes one of the potential causes of intergenerational transmission of inequality (1), and it is also the basis for various studies to establish research models. Through the intervention of different psychological changes, observing the changes at the macro and micro levels of the research object provides a good reference for analyzing its possible mechanisms (2). However, the changes in inequality psychology follow the direction of the balance needle, and the changes in the individual's internal environment also move, eventually positioning itself at a new balance point after another. Although the external performance of individuals at the new balance point will be considerably different, the psychological changes caused by long-term inequality differences will be invisibly imprinted on the changes in their own cellular and molecular levels and then further manifested (3).

Inequality is a stressor (4). Therefore, it is inevitable to have other stressors' characteristics. However, inequality is often a chronic and long-term stressor. Its potential impact on individuals is far beyond general stress. When we slow down and think carefully, we will find that our environment is ultimately 
an "equality-inequality" balance. Because each individual has a different level of psychological resilience, mental health is also different. The changes in the internal microenvironment are naturally diverse, and the final level of transmission between generations is even more significant. From this perspective, this balanced psychology has resulted from the "equality-inequality" interaction. However, as mentioned above, even if the "equality-inequality" reaches a temporary balance at this moment, this balance is very likely to be broken in the next second and develop towards a new equilibrium. It is precise because of the existing old balance that the new balance occurs based on it. Then, from this perspective, this balanced psychology has be-

\section{References}

1. Sharma S, Prakash A. Intergenerational transmission of inequality in psychological health. Sci Insig 2021; 39(5):379-390. DOI: https://doi.org/10.15354/si.21.re251

2. Panadero E. A review of self-regulated learning: Six models and four directions for research. Front Psychol 2017; 8:422. DOI: https://doi.org/10.3389/fpsyg.2017.00422

3. Vineis $P$, Avendano-Pabon M, Barros H, Bartley M, Carmeli C, Carra L, Chadeau-Hyam M, Costa G, Delpierre C, D'Errico A, Fraga S, Giles G, Goldberg M, Kelly-Irving M, Kivimaki M, Lepage B, Lang T, come the premise and reason for the following equilibrium of the "equality-inequality" interaction.

Based on the causal-effect alternation of balance psychology and the fact that psychological health is transmitted between generations caused by inequality, we encourage individuals to train their psychological resilience to achieve balance as quickly as possible. Positive psychological health inequality promotes development so that the indicator of balance points to the side that is beneficial to health. Conversely, suppose it is negative psychological health inequality. In that case, it encourages positive adjustments so that the balance indicator is as little as possible to the side that is not conducive to health.

Received: October 15, $2021 \quad$ ～Revised: October 20, $2021 \quad$ Accepted: October 22, 2021 